\title{
Flux Enhancement in Membrane Distillation Using Nanofiber Membranes
}

\author{
T. Jiříček, ${ }^{1,2}$ M. Komárek, ${ }^{2}$ J. Chaloupek, ${ }^{2}$ and T. Lederer ${ }^{2}$ \\ ${ }^{1}$ MemBrain s.r.o, Pod Vinicí 87, 47127 Stráž pod Ralskem, Czech Republic \\ ${ }^{2}$ Technical University of Liberec, Studentská 1402/2, 46117 Liberec 1, Czech Republic \\ Correspondence should be addressed to T. Jiříček; tomas.jiricek@membrain.cz
}

Received 1 March 2016; Accepted 8 May 2016

Academic Editor: Niranjan Patra

Copyright (C) 2016 T. Jiříček et al. This is an open access article distributed under the Creative Commons Attribution License, which permits unrestricted use, distribution, and reproduction in any medium, provided the original work is properly cited.

\begin{abstract}
Membrane distillation (MD) is an emerging separation technology, whose largest application potential lies in the desalination of highly concentrated solutions, which are out of the scope of reverse osmosis. Despite many attractive features, this technology is still awaiting large industrial application. The main reason is the lack of commercially available membranes with fluxes comparable to reverse osmosis. MD is a thermal separation process driven by a partial vapour pressure difference. Flux, distillate purity, and thermal efficiency are always in conflict, all three being strictly connected with pore size, membrane hydrophobicity, and thickness. The world has not seen the ideal membrane yet, but nanofibers may offer a solution to these contradictory requirements. Membranes of electrospun PVDF were tested under various conditions on a direct contact (DCMD) unit, in order to determine the optimum conditions for maximum flux. In addition, their performance was compared to commonly available PTFE, PE, and PES membranes. It was confirmed that thinner membranes have higher fluxes and a lower distillate purity and also higher energy losses via conduction across the membrane. As both mass and heat transfer are connected, it is best to develop new membranes with a target application in mind, for the specific membrane module and operational conditions.
\end{abstract}

\section{Introduction}

As sources of fresh water are becoming scarcer, new possibilities of sea and brackish water desalination are being investigated. Traditional technologies like reverse osmosis still cover most of the demand due to the high capacity, but issues like brine disposal and energy consumption need to be addressed in order to keep the need for desalination sustainable. Investigation of membrane distillation has gained popularity in recent years. Driven by temperature rather than pressure gradient, $\mathrm{MD}$ can concentrate feed solutions to their saturation point without a significant flux decline. The process can be driven by low grade waste heat, including solar and geothermal energy [1].

Indeed, membrane distillation is still waiting for its large industrial application, mainly because of the unavailability of proper hydrophobic membranes with high fluxes and low heat losses. MD performance is strongly influenced by the structure of the membrane, such as thickness, porosity, and pore size distribution. Such a membrane is required to provide an interface for the feed and distillate, while providing a resistance for them to mix. The optimum balance must be found between the conflicting requirements of high fluxes (thin membranes and large pores), low heat losses (thick membranes and small pores), and distillate purity (high liquid entry pressure and high contact angle).

(i) Membrane thickness plays a rather complicated role. Some authors state that the effect of membrane thickness is not completely clear [1]; others have found the optimum between 30 and $60 \mu \mathrm{m}$ [2]. Membranes with low thickness have less resistance to mass transport, while they suffer from poor heat efficiency due to temperature polarization and conduction losses across the membrane [3].

(ii) Pore size is critical for MD performance. Porous membranes do not exhibit a single pore size; rather they have a pore size distribution, ideally narrow with a sharp peak. Larger pores cause higher fluxes but also bear a danger of pore wetting. Several large pores 
can completely destroy the membrane performance by letting salty feed enter the distillate. The commonly used pore size ranges from 0.1 to $1 \mu \mathrm{m}$ [4].

(iii) Hydrophobicity and optimum membrane pore size are closely connected. Hydrophobic polymers, such as PVDF, PP, and PTFE, are most commonly used. PTFE has the best hydrophobic properties but it is difficult to process; hence most research on membranes has been carried out on PVDF [1].

(iv) In addition, not only pore size but also membrane porosity dictates flux and heat efficiency. Air inside the pores has a thermal conductivity smaller by order of magnitude than the polymeric film.

Nanotechnology has a significant potential in desalination by MD by providing a layer with unusual properties. Nanofibers are typically created by an electrostatic field from a polymer solution by electrospinning $[5,6]$. Various functional materials can be incorporated into the nanofibers during the electrospinning to enhance desired attributes, such as catalytic [7], biocidal [8, 9], or hydrophobic properties [10].

As recent papers covering electrospun nanofiber membranes [11, 12] declare high porosity and hydrophobicity, highly desirable properties for MD membranes, this paper covers an experimental comparison of nonwoven nanofiber membranes made from PVDF with commonly available film membranes, with the aim to investigate how flux and energy efficiency can be maximized. Previously published data with regard to membrane performance [13] have been confirmed and have been expanded with a comparison between various nanofiber membranes. None of the nanofiber membranes discussed in this paper have been altered by the introduction of hydrophobic additives to the polymer solution or by plasma treatment, as fluoropolymers themselves have excellent hydrophobicity and chemical resistance.

\section{Theory}

The flux across the membrane in DCMD is driven by a vapour pressure difference and can be represented simply by

$$
N=C \Delta p
$$

where $C$ is the membrane permeability and $\Delta p$ is the difference of partial vapour pressure between the hot feed and cold distillate and for pure water can be calculated using Antoine's equation. In this work it is assumed that the actual $\Delta p$ corresponds with $\Delta T$ between the feed and distillate, neglecting the effect of temperature polarization. At higher salinities, the actual feed vapour pressure is influenced by the activity of water $a_{w}$, and negative fluxes can occur at $\Delta T=0^{\circ} \mathrm{C}$ due to the osmotic gradient [13].

Mass transport has the same direction as the conduction and convection of heat. The energy efficiency is the ratio of the efficient heat flux caused by the vapour flux and the total heat flux across the membrane and is calculated by

$$
E=\frac{N \Delta H A}{m C_{p} \Delta T},
$$

TABLE 1: List of the tested membranes.

\begin{tabular}{lcc}
\hline $\begin{array}{l}\text { Membrane } \\
\text { name }\end{array}$ & Lamination & $\begin{array}{c}\text { Polymer thermal } \\
\text { conductivity }\left(\mathrm{W} \mathrm{m}^{-1} \mathrm{~K}^{-1}\right)\end{array}$ \\
\hline PTFE & - & 0.25 \\
PE & - & 0.43 \\
PES & - & 0.15 \\
NanoPVDF03 & 2 sides & 0.19 \\
NanoPVDF04 & 1 side & 0.19 \\
NanoPVDF06 & 1 side & 0.19 \\
\hline
\end{tabular}

where $N$ is flux, $\Delta H$ is the enthalpy of condensation, $A$ is the effective membrane area, $m$ is the mass flowrate along the membrane, $C_{p}$ is the heat capacity, and $\Delta T$ is the temperature difference at the inlet and outlet of the module. Heat loss through the membrane can be reduced by optimizing membrane thickness, porosity, and thermal conductivity.

\section{Materials and Methods}

3.1. Membranes. Commercially available membranes are mainly made of PP, PTFE, PVDF, and PE [14]. Two kinds of membranes were tested in this study: commercial polymeric film membranes made from PTFE, PE, and PES and PVDF nanofiber membranes, supported from one or two sides by a bicomponent PP/PE 70/30 spunbond. The properties of the membranes are summarized in Table 1.

The PVDF nanofiber layers were prepared by continuous needleless electrospinning process. PVDF Solef 1015 was purchased from the "Solvay-Specialty Polymers Co." and dissolved in N,N-Dimethylformamide from Sigma-Aldrich. The solution was electrospun using the Nanospider ${ }^{\mathrm{TM}}$ (CZ), equipped with a $0.2 \mathrm{~mm}$ wire electrode and a moving applicator head. The voltage was set in the range of 50 to $70 \mathrm{kV}$ and the distance between the electrodes was constantly $175 \mathrm{~mm}$. Relative humidity was kept under $40 \%$ to minimize the formation of bead defects. Production speed was varied according to the desired nanofiber sheet thickness. The nanofibers were collected on a nonadhesive paper substrate and laminated on a Meyer (DE) flatbed laminator at $1.5 \mathrm{~m} \mathrm{~min}^{-1}$, using a pressure of $10 \mathrm{~N} \mathrm{~cm}^{-2}$ at $135^{\circ} \mathrm{C}$.

3.2. DCMD Setup. The membrane performance was tested on a bench scale DCMD experimental setup, built around a flat sheet membrane module from Aquastill (NL), with a rather large effective membrane area of $0.05 \mathrm{~m}^{2}$ (Figure 1). The tests of membrane permeability were carried out with demineralised water in both circuits. The retention tests had demineralised water in the distillate circuit, and sodium chloride solution in the feed, ranging from 0 to $100 \mathrm{~g} \mathrm{~kg}^{-1}$. The circulation was countercurrent with a horizontal position of the MD module, hot feed on the bottom, and cold distillate on top. The recirculation was powered by a peristaltic pump with a two-way rotation head, with a crossflow velocity of between 45 and $85 \mathrm{~mm} \mathrm{~s}^{-1}$. The effect of feed concentration on flux and membrane retention was measured at $85 \mathrm{~mm} \mathrm{~s}^{-1}$. In all of the experiments the logarithmic mean temperature 


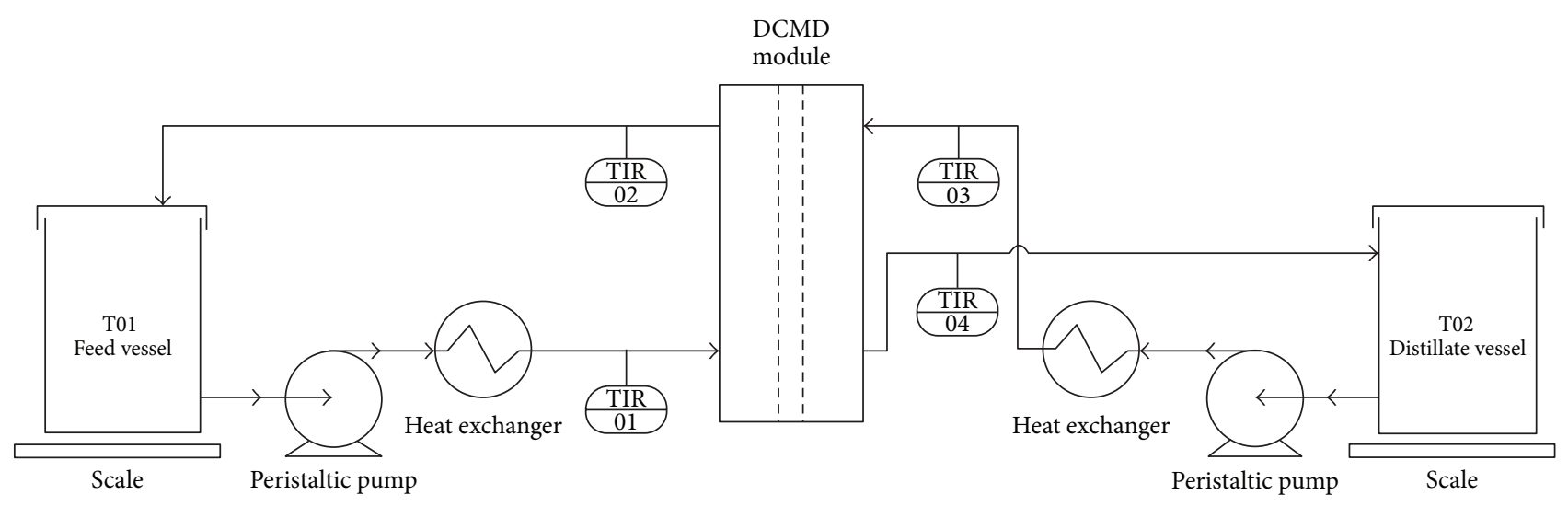

FIgURE 1: Schematic MD setup.

TABle 2: Membrane properties.

\begin{tabular}{|c|c|c|c|c|c|c|}
\hline Membrane name & Thickness $(\mu \mathrm{m})$ & $\begin{array}{c}\text { Mean pore size } \\
(\mu \mathrm{m})\end{array}$ & $\begin{array}{c}\text { Maximum pore } \\
\text { size }(\mu \mathrm{m})\end{array}$ & LEP (bar) & $\begin{array}{c}\text { Bubble point } \\
\text { pressure (bar) }\end{array}$ & Contact angle \\
\hline PTFE & 72.1 & 0.22 & 0.276 & 9 & 2.320 & 136 \\
\hline $\mathrm{PE}$ & 82.1 & 0.34 & 0.741 & 3 & 0.885 & 120 \\
\hline PES & 72.5 & 0.55 & 0.620 & 2.9 & 1.303 & 131 \\
\hline NanoPVDF03 & 13.9 & 1.77 & 2.155 & $<0.64$ & 0.297 & 123 \\
\hline NanoPVDF04 & 15.5 & 1.07 & 1.364 & $<0.65$ & 0.469 & 135 \\
\hline NanoPVDF06 & 22.6 & 0.92 & 1.060 & $<0.66$ & 0.601 & 129 \\
\hline
\end{tabular}

difference (LMTD) was kept constant at $10^{\circ} \mathrm{C}$, with the feed inlet temperature set to $60^{\circ} \mathrm{C}$ by a Julabo F12 hot bath and a cooling water circuit. Temperatures were measured by four thermocouples in the inlet and outlet pipes. The flux was calculated from the difference of mass on the feed and distillate A\&D EK-12Ki scales. The electrical conductivity was measured by WTW TetraCon probes connected to WTW Mutli9430 and WTW Multi350i. Retention was calculated as $=1-c_{d} / c_{f}$, where $c_{f}$ is the feed concentration and $c_{d}$ is the distillate concentration. Data analysis was performed using GraphPad Prism 6 and Microsoft Excel.

3.3. Porometry. POROMETER 3G by Quantachrome was used to measure the bubble point pressure and the maximum and average pore diameter, by using a wet-dry flow method with a wetting liquid Porefil. Water was used as a wetting liquid to estimate the liquid entry pressure (LEP), which is the pressure at which water wets the membrane pores.

3.4. Contact Angle. The contact angle was measured by Optical Tensiometer THETA QC from Attension, using demineralised water. This device automatically carries out the image analysis on the drop and gives the average of the right and left angle.

3.5. Membrane Structure and Thickness. Membrane structure and thickness were studied on a Tescan Vega3SB (CZ) high vacuum scanning electron microscope at an acceleration voltage of $30.0 \mathrm{kV}$. All of the samples were coated with a $5 \mathrm{~nm}$ thick layer of gold/palladium using a sputter coater (Quorum
Technologies, England). The cross section thicknesses of the membranes were obtained by cutting the membranes with a sharp razor, imaging the cut by SEM. Image analysis software from Tescan was used to measure the nanofiber diameters and cross section thickness of the membrane.

\section{Results and Discussion}

4.1. Membrane Characterisation. The tested membranes were characterised in order to explain the differences in their MD performance. The relevant parameters are summarized below (Table 2). The most obvious difference between the standard film membranes and the nanofiber layers is the membrane thickness, the latter being much thinner. Also, the pore size distribution is quite different, interestingly with the nonwoven membranes seeming to have larger pores. Nonwoven layers do not have pores as such but the porometer assumes unitary tubular pores.

Two parameters characterise membrane hydrophobicity, contact angle, and LEP.

(i) Considering that PTFE membranes are renowned for their superb hydrophobicity, it is a great achievement to find that PVDF layers have their contact angle in the same range.

(ii) However, when it comes to LEP, nanofiber layers cannot sustain a pressure of more than 0.64 bar, whereas water was able to penetrate PTFE pores only after 9 bar was applied. As no posttreatment was used on the laminated layers (e.g., $\mathrm{CF}_{4}$ plasma), it 

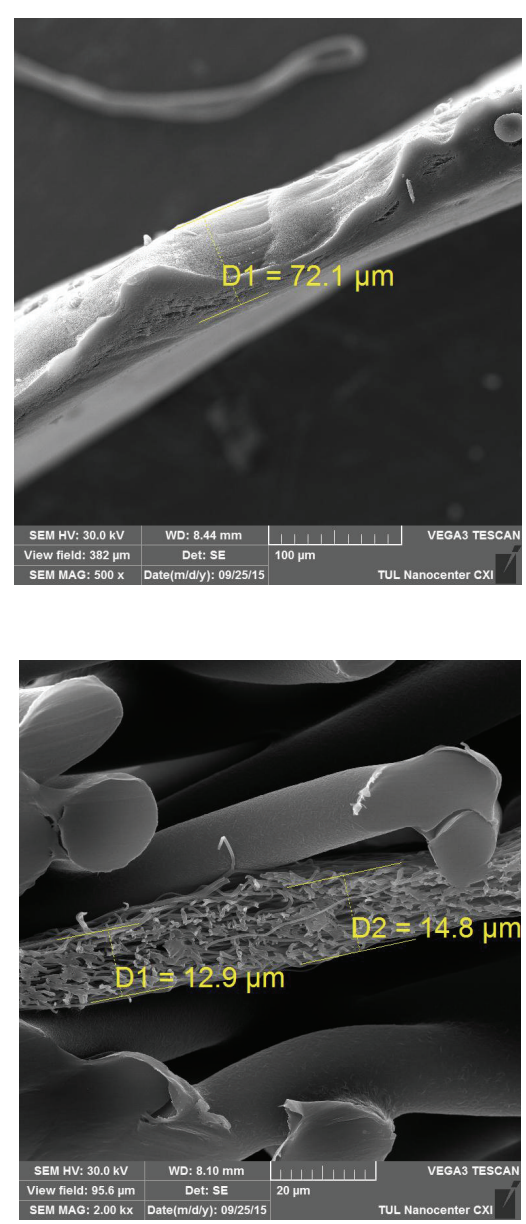
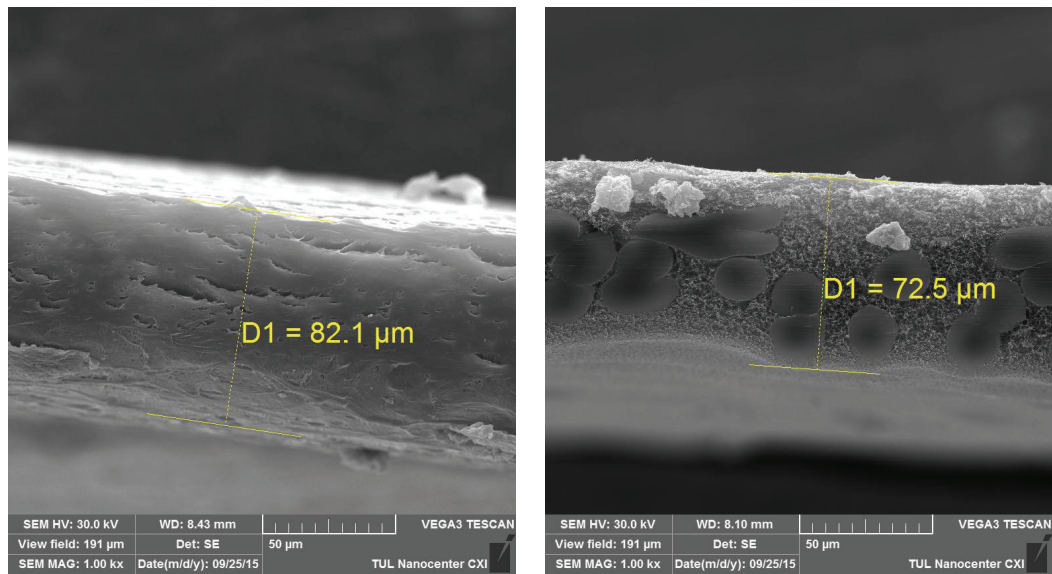

(a)
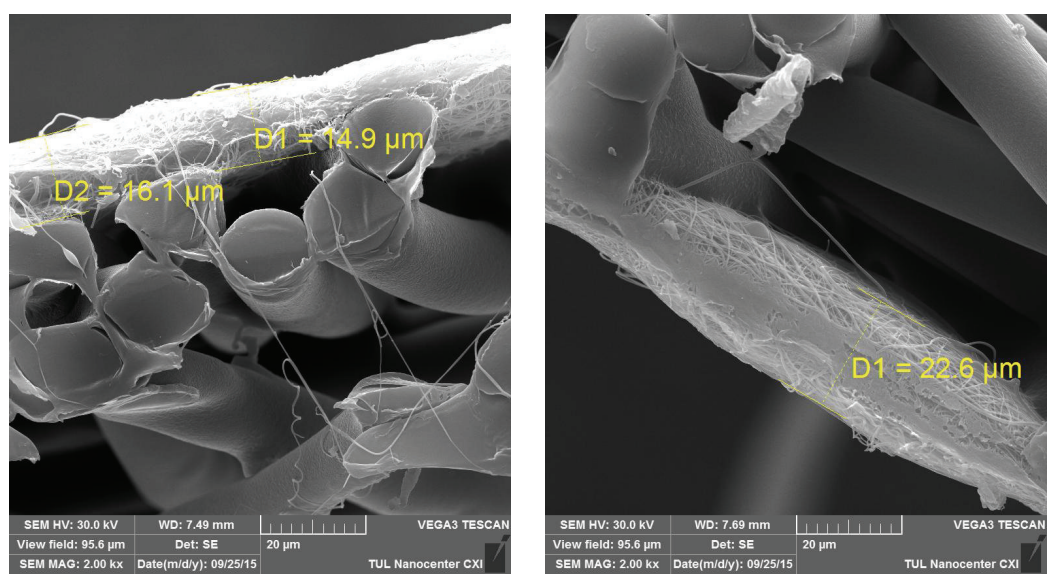

(b)

Figure 2: Cross section of membranes ((a) PTFE 1000x, PE 1000x, and PES 500x and (b) NanoPVDF03 2000x, NanoPVDF04 2000x, and NanoPVDF06 2000x).

is suggested that the lamination step compromised otherwise excellent PVDF hydrophobicity.

A cross section of the membranes with the measurement of their thickness is shown in Figure 2. The film membranes in Figure 2(a) show compression from a razor cut. Figure 2(b) shows the nanofiber membranes. NanoPVDF03 has a supporting spunbond from both sides, whereas NanoPVDF04 and NanoPVDF06 have it only from one side.

The film membranes have different structures from each other (Figure 3). PTFE has the finest structure, PE has rather large shapes, and PES has small circular pores. The nanofibers have a similar look, and in all cases the PVDF fiber diameter was around $200 \mathrm{~nm}$. The structure is not uniform, with occasional polymer drops or fusing caused by nonevaporated solvent.

4.2. Flux. Figure 4 shows the effect of crossflow velocity on demineralised water flux. All of the nanofiber membranes respond better to an increase in crossflow velocity. NanoPVDF04 with one-side lamination shows the highest fluxes thanks to its small thickness, even though thinner membranes should suffer more from temperature polarization. Larger pores do not contribute to flux increase, as pore size beyond $0.3 \mu \mathrm{m}$ should not have a significant effect [15].

Two-side lamination spoils the membrane performance. NanoPVDF03 has the same thickness as NanoPVDF04 but the fluxes are significantly smaller at all crossflow velocities. The effect of crossflow velocity is smaller on the film membranes, and at smaller flowrates their fluxes are comparable to the better nanofiber membranes.

4.3. Energy Efficiency. Energy efficiency should increase with higher crossflow velocities (Figure 5), as the effective heat of condensation increases with flux, whereas the lossy heat of conduction remains about the same. This is stated because the driving force was set according to LMTD, which accounts for all four inlet and outlet temperatures and not only for the feed and distillate $\Delta T$. There is a clear difference between the thick film and thin nonwoven membranes, the latter having much worse energy efficiency. The thermal conductivity of PTFE is about the same as PVDF but thanks to the PTFE thickness and superb hydrophobicity, it is assumed that only vapour is present in the membrane pores and heat losses are negligible. 

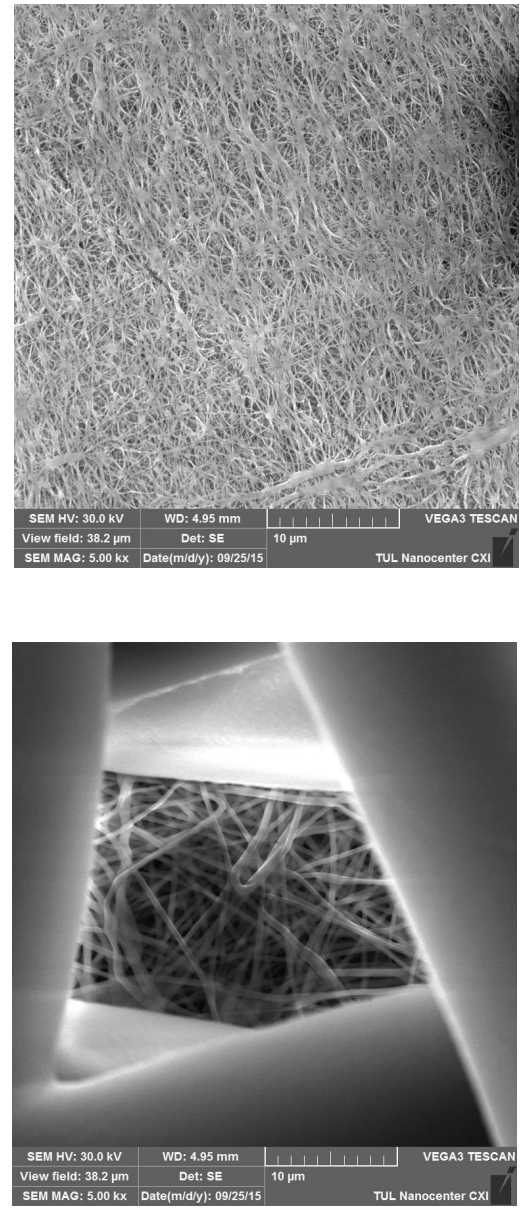
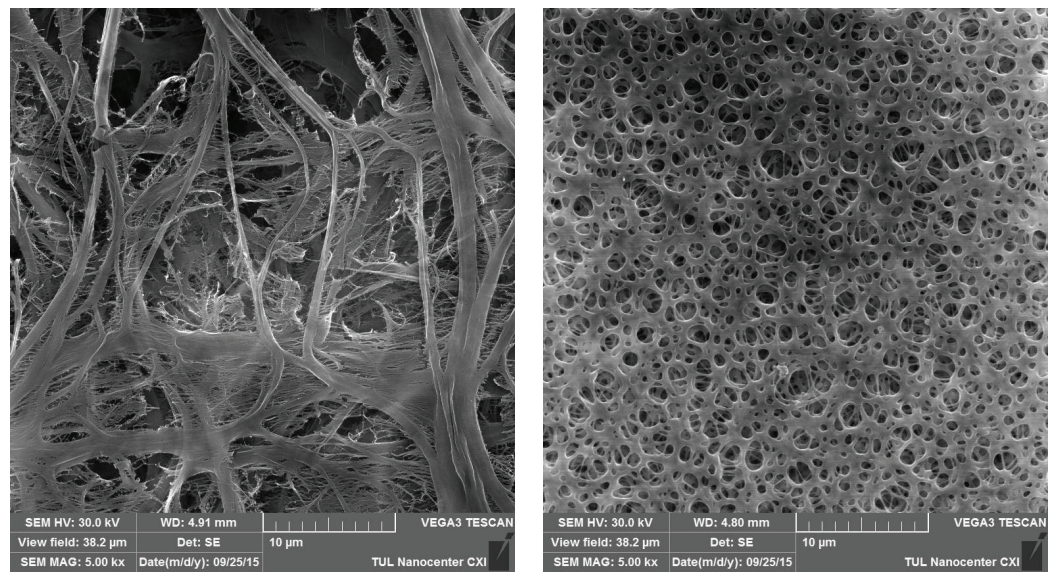

(a)
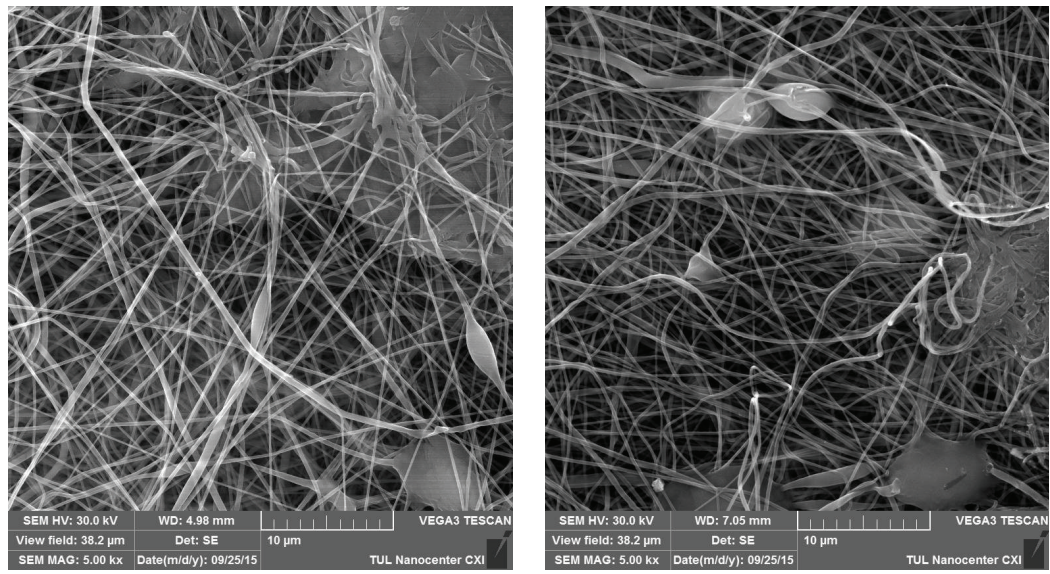

(b)

Figure 3: Perpendicular SEM micrographs of the membrane structure 1000x ((a) PTFE, PE, and PES and (b) NanoPVDF03, NanoPVDF04, and NanoPVDF06).

Despite its large membrane area, the estimation of energy efficiency on this current experimental setup is not very precise, as reflected in the fact that the PTFE efficiency is larger than $100 \%$ but the nanofibers are still behind. With large-scale application in mind, though, this may not be such a drawback because MD is considered to be driven by cheap low grade waste heat, and low fluxes of common membranes are a more significant disadvantage than suboptimal energy efficiency.

4.4. Retention. There are two aspects with regard to membrane retention: whether feed concentration reduces membrane flux and whether it affects distillate purity. In short, all of the tested membranes had excellent retention of above $99.7 \%$. The only exception was NanoPVDF03 which had retention of around $85 \%$ at the highest concentration, and it is not displayed in Figure 6 due to axis scale. Compared to film membranes, nanofiber membranes are affected by the feed concentration and even though the retention is excellent the behaviour is different. The structure of the nonwoven layers is different, pore size distribution is wider (see the difference between maximum and mean pore size in Table 2), and an occasional imperfection may cause salt to penetrate from the feed to the distillate. This was not caused by membrane wetting as the clean water flux before and after the test was unchanged.

To improve readability only four membranes are displayed in Figure 7. NanoPVDF04 again has the highest flux when the feed contains only demineralised water. Increasing the feed salinity decreases the flux through all of the membranes. The PTFE membrane seems to be least affected and shows the highest flux at $100 \mathrm{~g} \mathrm{~kg}^{-1}$. NanoPVDF03 shows the lowest fluxes in accordance with the previous observations with clean water (Figure 4), although interestingly it is quite comparable to the rest at the maximum concentration.

\section{Conclusions}

Membrane thickness proved to be a crucial parameter when high fluxes are most important. With crossflow velocities of above $80 \mathrm{~mm} \mathrm{~s}^{-1}$ nonwoven nanofiber membranes have unrivalled permeability. However, film membranes have their strengths as well and PTFE in particular demonstrates that decades of development have been worth it. It has by far the 


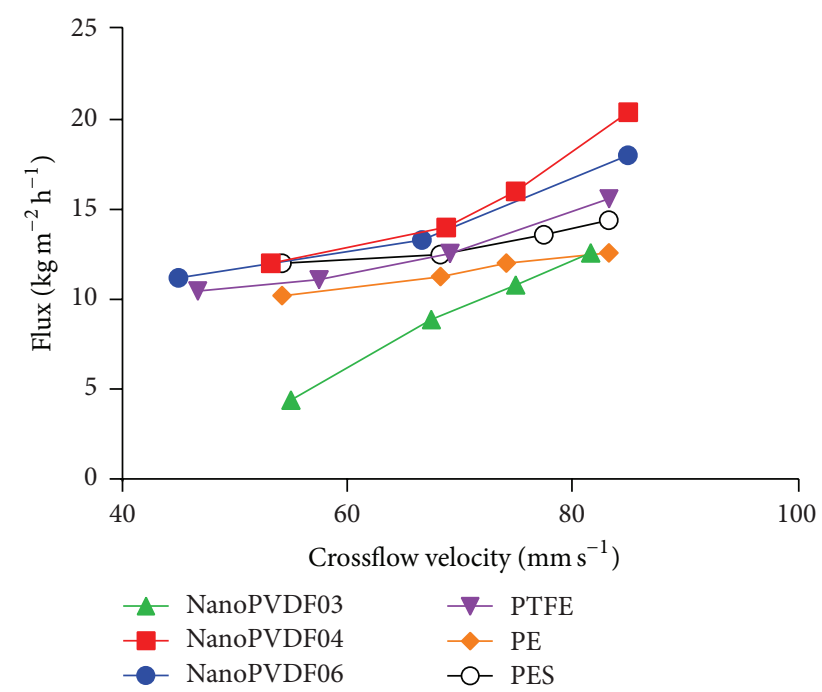

FIGURE 4: The effect of crossflow velocity on clean water flux.

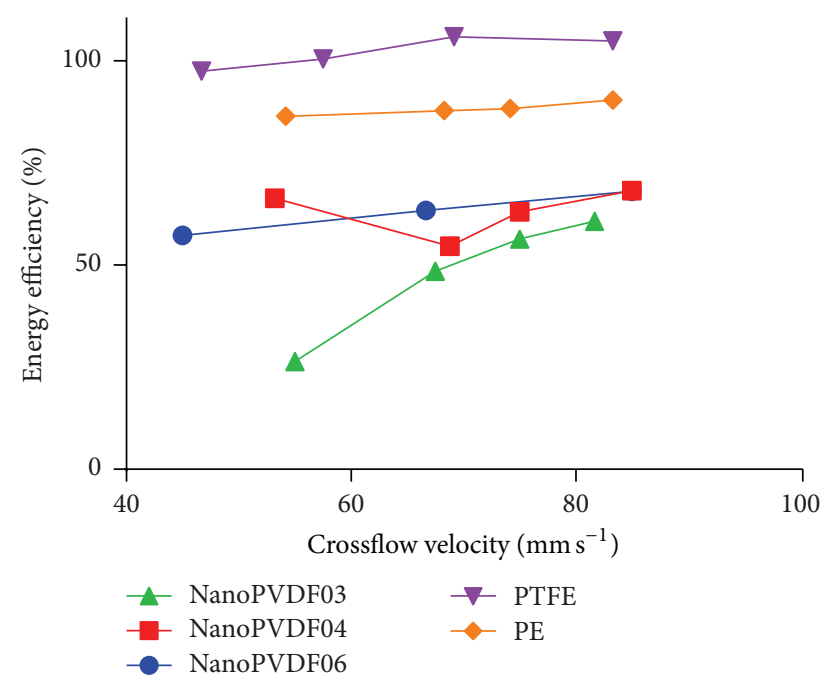

FIGURE 5: The effect of crossflow velocity on energy efficiency.

best energy efficiency and also its fluxes at higher salinities are better than any other membrane tested.

Thus, selection of the right membrane is critical for the MD process, and it is necessary to bear the target application in mind. It has been confirmed that for slightly saline water up to $50 \mathrm{~g} \mathrm{~kg}^{-1}$ thinner membranes have higher permeability, but when feed salinity increases then PTFE has no competition. If the application is for the treatment of solutions that are beyond the range of reverse osmosis due to high osmotic pressure, then PTFE would be the right choice at the moment. On the other hand, when diluted solutions are treated, high fluxes are crucial and overall technological simplicity is required; nanofiber membranes may certainly have their purpose. Typically, any treatment of brackish or very hard groundwater will have its bottleneck in the overall hydraulic performance. Therefore, a very promising application is in power plants-there is enough waste heat

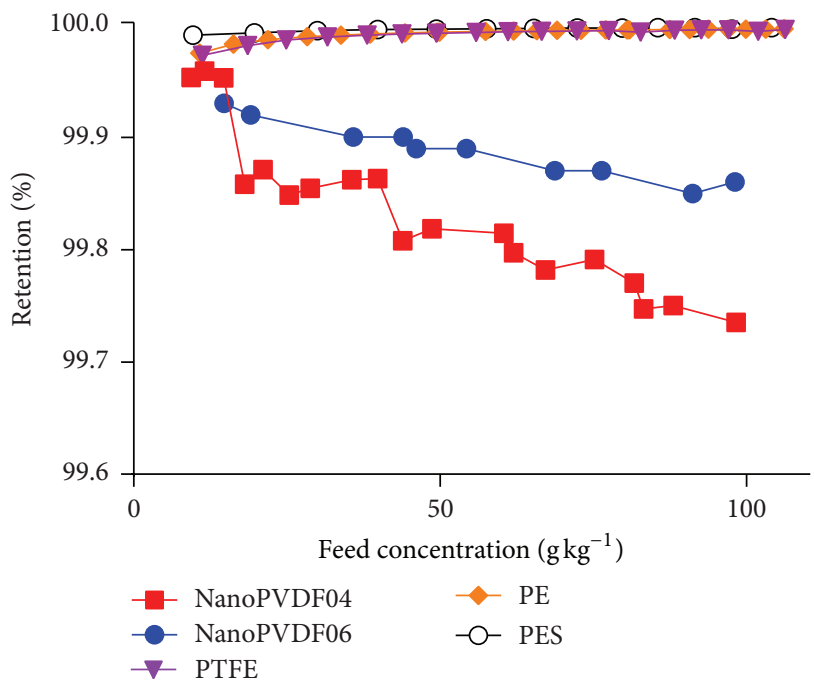

FIGURE 6: Membrane retention varies between nanofiber and film membranes.

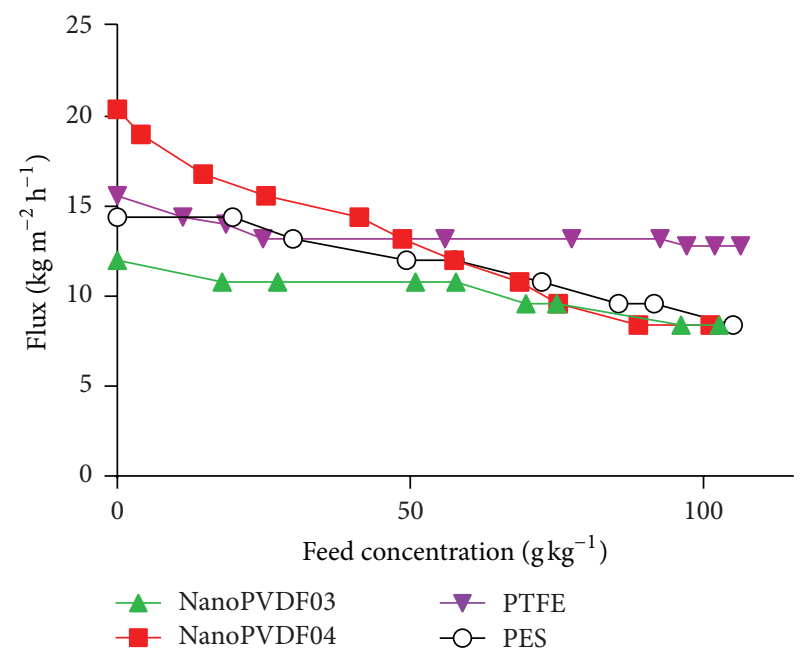

FIGURE 7: The effect of feed concentration on membrane flux.

and also a requirement for softened cooling water, which is usually prepared from surface water.

It has been shown that flux, energy efficiency, and distillate purity are closely connected and one cannot be increased without sacrificing the other two. High fluxes are the most desirable progress in MD these days. Nanofiber membranes suggest a solution but further improvement of membrane hydrophobicity in terms of LEP would be required for most future large-scale applications.

\section{Abbreviations and Symbols}

$N: \quad$ Flux $\left(\mathrm{kg} \mathrm{m}^{-2} \mathrm{~h}^{-1}\right)$

$C: \quad$ Permeability $\left(\mathrm{kg} \mathrm{m}^{-2} \mathrm{~h}^{-1} \mathrm{bar}^{-1}\right)$

$\Delta p$ : Vapour pressure difference (bar)

$E: \quad$ Energy efficiency (\%)

$\Delta H$ : Enthalpy of condensation $\left(\mathrm{J} \mathrm{kg}^{-1}\right)$

A: $\quad$ Membrane area $\left(\mathrm{m}^{2}\right)$ 


$\begin{array}{ll}m: & \text { Mass flowrate }\left(\mathrm{kg} \mathrm{s}^{-1}\right) \\ C_{p}: & \begin{array}{l}\text { Heat capacity at constant pressure } \\ \left(\mathrm{J} \mathrm{kg}^{-1} \mathrm{~K}^{-1}\right)\end{array} \\ \Delta T: & \text { Temperature difference }\left({ }^{\circ} \mathrm{C}\right) \\ \text { LMTD: } & \text { Logarithmic mean temperature difference } \\ & \left({ }^{\circ} \mathrm{C}\right)\end{array}$

\section{Competing Interests}

The authors declare that there is no conflict of interests regarding the publication of this paper.

\section{Acknowledgments}

The presented results were achieved in the framework of the project LO1418 "Progressive Development of Membrane Innovation Centre," supported by the program NPU I Ministry of Education, Youth and Sports of the Czech Republic, using the infrastructure of the Membrane Innovation Centre. The research was also supported by the Ministry of Education, Youth and Sports in the framework of the targeted support of the "National Programme for Sustainability I" LO 1201 and the OPR\&DI project "Centre for Nanomaterials, Advanced Technologies and Innovation," CZ.1.05/2.1.00/ 01.0005. The authors would also like to thank Bart Nelemans of Aquastill for providing the film PTFE, PES, and PE membranes.

\section{References}

[1] E. Drioli, A. Ali, and F. Macedonio, "Membrane distillation: recent developments and perspectives," Desalination, vol. 356, pp. 56-84, 2015.

[2] F. Laganà, G. Barbieri, and E. Drioli, "Direct contact membrane distillation: modelling and concentration experiments," Journal of Membrane Science, vol. 166, no. 1, pp. 1-11, 2000.

[3] S. Al-Obaidani, E. Curcio, F. Macedonio, G. Di Profio, H. AlHinai, and E. Drioli, "Potential of membrane distillation in seawater desalination: thermal efficiency, sensitivity study and cost estimation," Journal of Membrane Science, vol. 323, no. 1, pp. 85-98, 2008.

[4] A. Alkhudhiri, N. Darwish, and N. Hilal, "Membrane distillation: a comprehensive review," Desalination, vol. 287, pp. 2-18, 2012.

[5] D. Lukáš, A. Sarkar, L. Martinová et al., "Physical principles of electrospinning (electrospinning as a nano-scale technology of the twenty-first century)," Textile Progress, vol. 41, no. 2, pp. 59140, 2009.
[6] F. Yener and O. Jirsak, "Comparison between the needle and roller electrospinning of polyvinylbutyral," Journal of Nanomaterials, vol. 2012, Article ID 839317, 6 pages, 2012.

[7] C. Basheer, "Nanofiber-membrane-supported $\mathrm{TiO}_{2}$ as a catalyst for oxidation of benzene to phenol," Journal of Chemistry, vol. 2013, Article ID 562305, 7 pages, 2013.

[8] A. Haider, S. Kwak, K. C. Gupta, and I.-K. Kang, "Antibacterial activity and cytocompatibility of PLGA/CuO hybrid nanofiber scaffolds prepared by electrospinning," Journal of Nanomaterials, vol. 2015, Article ID 832762, 10 pages, 2015.

[9] F. Yalcinkaya, M. Komarek, D. Lubasova, F. Sanetrnik, and J. Maryska, "Preparation of antibacterial nanofibre/nanoparticle covered composite yarns," Journal of Nanomaterials, vol. 2016, Article ID 7565972, 7 pages, 2016.

[10] N. Nuraje, W. S. Khan, Y. Lei, M. Ceylan, and R. Asmatulu, "Superhydrophobic electrospun nanofibers," Journal of Materials Chemistry A, vol. 1, no. 6, pp. 1929-1946, 2013.

[11] A. Razmjou, E. Arifin, G. Dong, J. Mansouri, and V. Chen, "Superhydrophobic modification of $\mathrm{TiO}_{2}$ nanocomposite PVDF membranes for applications in membrane distillation," Journal of Membrane Science, vol. 415-416, pp. 850-863, 2012.

[12] C. Yang, X.-M. Li, J. Gilron et al., "CF4 plasma-modified superhydrophobic PVDF membranes for direct contact membrane distillation," Journal of Membrane Science, vol. 456, pp. 155-161, 2014.

[13] L. Eykens, I. Hitsov, K. De Sitter et al., "Influence of membrane thickness and process conditions on direct contact membrane distillation at different salinities," Journal of Membrane Science, vol. 498, pp. 353-364, 2016.

[14] B. L. Pangarkar, M. G. Sane, and M. Guddad, "Reverse osmosis and membrane distillation for desalination of groundwater: a review," ISRN Materials Science, vol. 2011, Article ID 523124, 9 pages, 2011.

[15] M. I. Ali, E. K. Summers, H. A. Arafat, and J. H. Lienhard V, "Effects of membrane properties on water production cost in small scale membrane distillation systems," Desalination, vol. 306, pp. 60-71, 2012. 

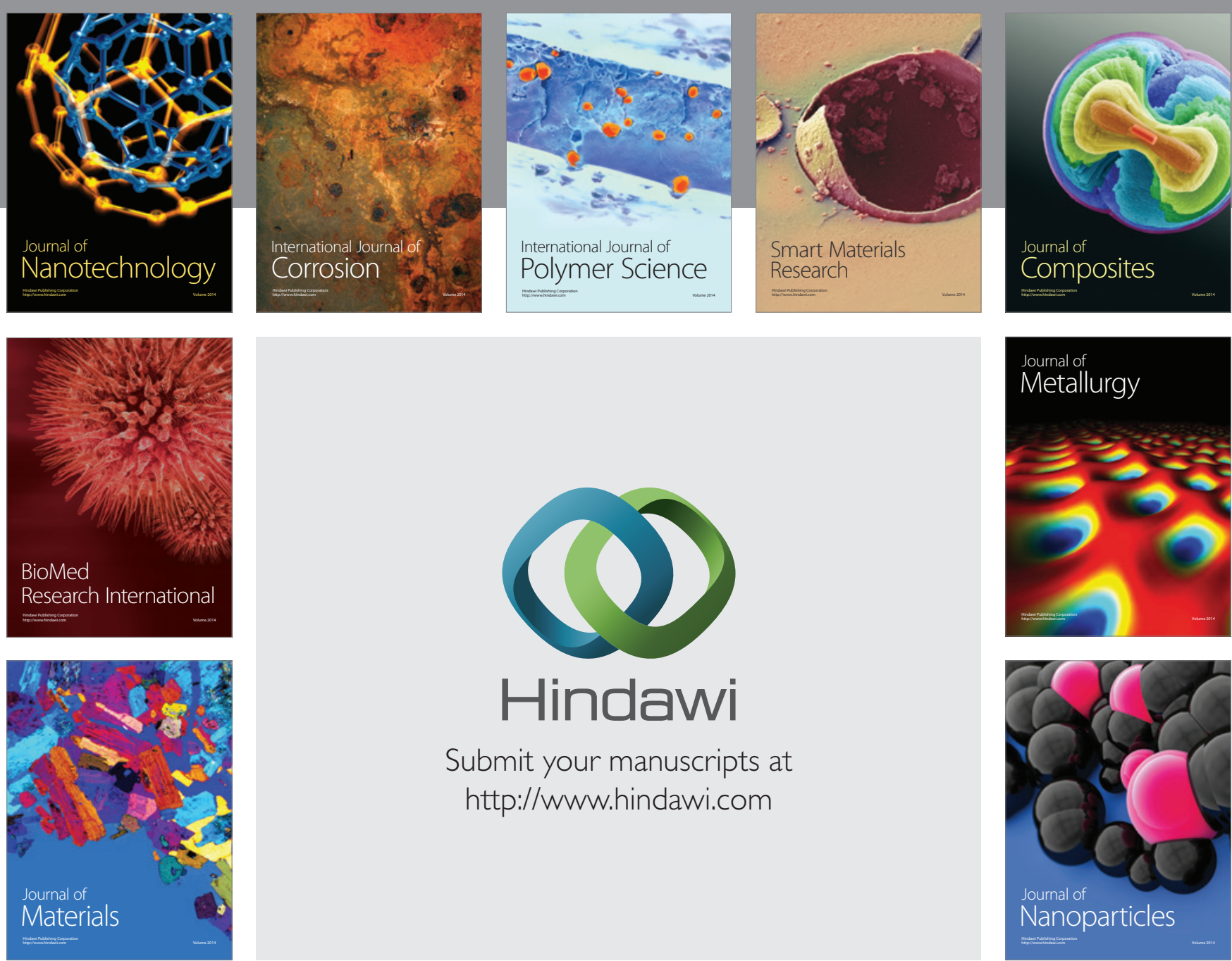

\section{Hindawi}

Submit your manuscripts at

http://www.hindawi.com

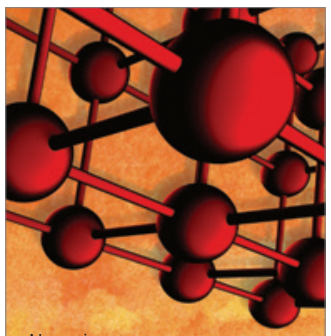

Materials Science and Engineering
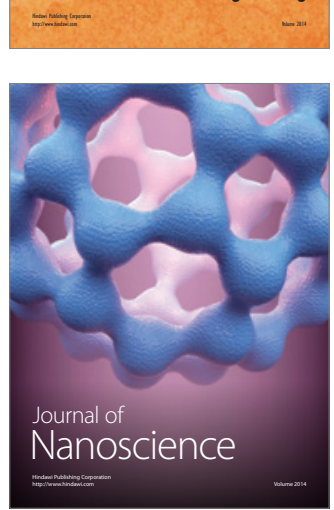
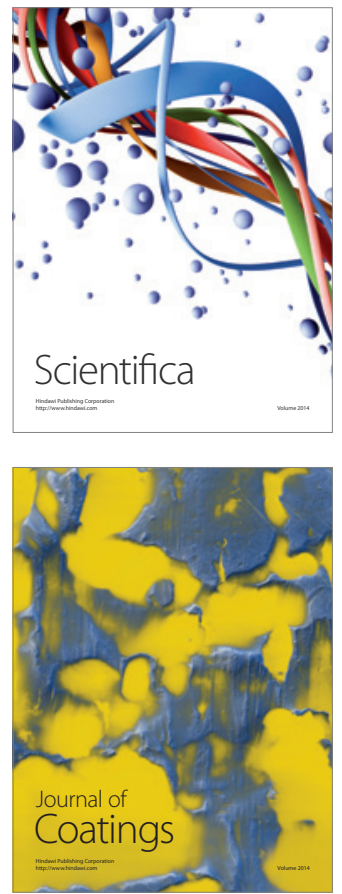
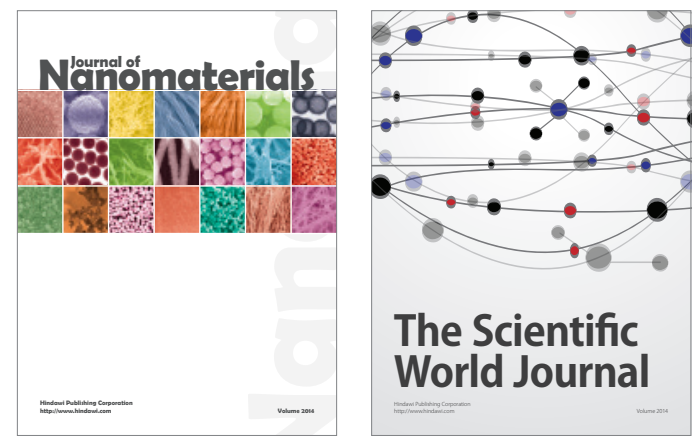

The Scientific World Journal
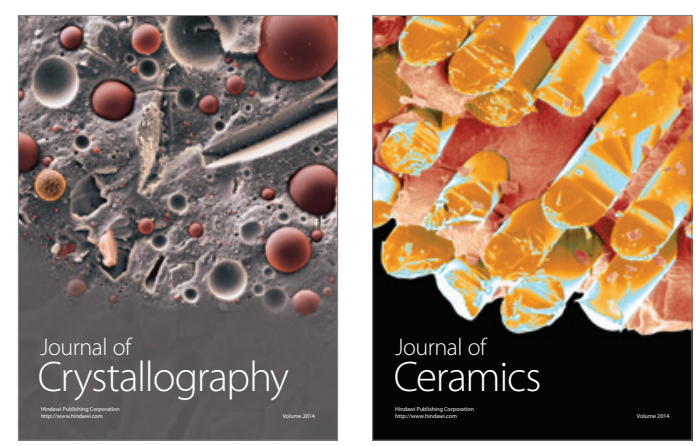
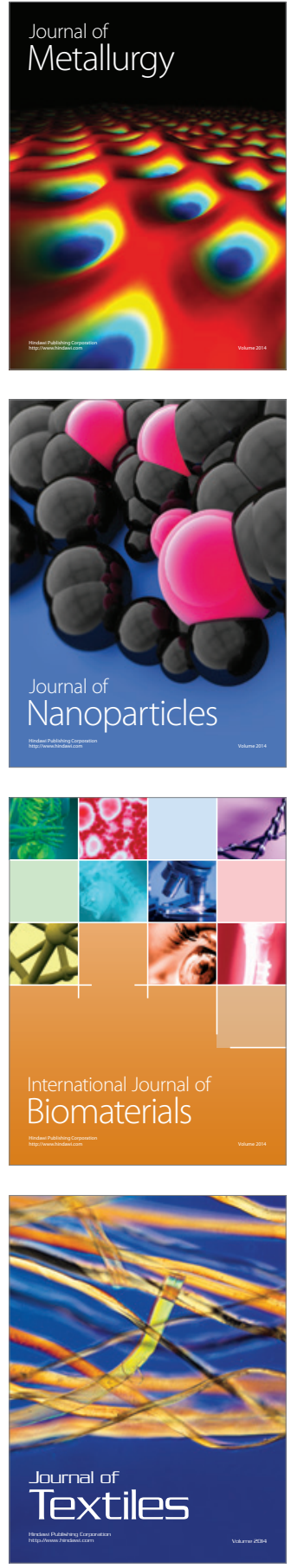